\title{
The Future of Public Sector HRM in Mauritius from an Accountability Perspective
}

\author{
Anita Ramgutty-Wong \\ Department of Management, Faculty of Law and Management, University of Mauritius, Le Reduit, Mauritius \\ Email: rwong@uom.ac.mu
}

Received November 2013

\section{Abstract}

The collective vision of sustainable human development, as expressed by the international community in the UN Millennium Declaration, is a challenge for countries that are not adequately equipped to face the challenges of globalization. A key step in the right direction is the institutionalization of a transparent and accountable public sector that would be truly responsive to a country's need. As in other parts of the world, Mauritius has embarked on reform programs in response to new opportunities brought about by globalization and the "rise" of Africa. Although public sector reform has appeared on the agenda of successive governments since early 1990s, many critics feel that the progress could have been faster and more substantial. In particular, the traditional omnipresent state has been much criticized for keeping bureaucratic red tape and inefficiency, and generally a poor level of accountability with respect to its obligations. Thus, in order to fully capitalize on the spreading trend of globalization and the immense opportunities offered by the "rise" of Africa, it becomes necessary to look into the reforms to the Public Services as far as human resource management is concerned. This paper lays down the state of affairs in this area and proposes an analysis of the pertinence and efficacy of such reforms from an accountability perspective. Many positive results are noted amongst those ministries that have implemented the Performance Management System, but many other findings are also problematic, such as: 1) Lack of clarity on how PLM is promoting organizational goals; 2) Many staffs unconvince that PMS will help improve their career prospects; 3) Few public sector organizations are able to use the PMS as a basis for staff training plans or for promotion decisions; 4) The appraisal forms are cumbersome and unrealistic; 5) PMS seems to be missing the point of addressing real management challenges; 6) Poor senior management "focus" and commitment to PMS. These findings echo what already exists in many case study reports and literature reviews, wherein we find that performance management systems seem to fall foul of their lofty ideals. Nevertheless, the Mauritian Public Sector has implemented a Performance-Based Budgeting (PBB) system, as a driving force behind the emphasis on identifying goals and measures. This complements the PMS in pushing public sector departments and ministries in the direction of aligning their activities, including HRM, toward achieving strategic goals and measuring progress toward those goals. This can help clarify future direction, establish priorities, initiate program performance improvement, increase effectiveness and accountability, and help managers improve service delivery, decision-making and internal management. But from good intentions to real implementation, the gap is yet to be addressed. Po- 
litical interference, budgetary constraints, top-down management and centralized recruitment and selection are definite barriers to an HRM Accountability System.

\author{
Keywords \\ HRM; HR Accountability; Performance Management; Public Sector; Mauritius
}

\title{
1. Introduction
}

The collective vision of sustainable human development, as expressed by the international community in the United Nations Millennium Declaration, becomes more difficult for those countries not adequately equipped to face the challenges of globalization. Consequently, its adverse effects have to be mediated by governments with appropriate reforms to governance structures. A key step in this direction is the institutionalization of a transparent and accountable public sector that would be truly responsive to a country's specific needs. Partnerships between the private and public sectors can be best optimized when the government and other public sector entities operate on principles of transparency-by making information available and accessible-and accountability-by being answerable for their decisions and actions. Transparency and accountability are interrelated and mutually reinforcing concepts. Without transparency, which is unfettered access to timely and reliable information on decisions and performance, it would be difficult to call public sector entities to account. Unless there is accountability that is mechanisms to report on the usage of public resources and consequences for failing to meet stated performance objectives, transparency would be of little value. The existence of both conditions is a prerequisite to an effective, efficient and equitable management in public institutions. And as such, both conditions are also necessary in trying to achieve sustainable human development through better governance in an era of globalization. Mauritius has frequently taken pride in its Transparency Index as compared to other countries. The purpose for demanding transparency is to allow citizens and markets to hold institutions accountable for their policies and performance.

As in other parts of the world, Mauritius has embarked on reform programs in response to new opportunities brought about by globalization and the "Rise of Africa". Mauritius has thus constantly and perhaps recently more intensively tried to revitalize the economy through the promotion of business and investment in both traditional and new sectors, to serve as the main engine of economic growth. Global changes coupled with technological advancement through fierce competition are impacting on the environment, thereby calling for better governance through effective service delivery. Reforms have focused on improvements in outcomes to transform the Public Sector. The investment climate has been much improved, notably thanks to a series of measures aimed at facilitating business. In 2013, Mauritius ranked $19^{\text {th }}$ worldwide in "ease of doing business", the only country-with South Africa-in the African region to even find a place in this international ranking [1]. Although public sector reform has appeared on the agenda of successive governments since early 1990s, many critics feel that the progress could have been faster and more substantial. In particular, the traditional omnipresent State has been much criticized for paying lip service to the slogan of facilitating business, by keeping bureaucratic red tape and inefficiency, and generally a poor level of accountability with respect to its obligations. Nevertheless, the need has been recognized for establishing a modern information and communication infrastructure as well as streamlining bureaucracies to facilitate economic development, and indeed, some reforms have emphasized the necessity for increasing the efficiency and the effectiveness of public sector operations, in particular human resource capabilities and actions, such as:

- A Ministry with a clear mandate for Civil Service Reforms.

- A Unit that would focus on the articulation and implementation of a Reform strategy.

- A Steering Committee that would look into the articulation of a PMS strategy.

- Setting up of a Performance Management System.

- Institution of the Performance-Based Budgeting system.

- The imminent setting up of a Civil Service College.

- In its last Budget Speech, [2] Government has announced.

o A Rs 50 million budget for the implementation of a new Civil Service Performance Related Incentive Scheme;

o A performance agreement to be signed between the Secretary to Cabinet and Head of the Civil Service and each Accounting Officer, stipulating the Key Performance Indicators for each Ministry; 
o A Civil Service Modernization Program including.

- New Strategic Policy Unit under the Prime Minister’s Office;

- A program to upgrade skills through the Civil Service College; and

- Extensive use of latest technology for the delivery of public services.

The main purposes/aims of reforms are to change the role of government from regulator to facilitator, with an emphasis on refocusing and narrowing of overall responsibilities such as identifying regulatory constraints to investment and other economic activities, improving delivery of services to the people, and making efforts for simplified rules and procedures, decentralization and delegation.

Thus, in order to fully capitalize on the spreading trend of globalisation and the immense opportunities offered by the 'rise' of Africa, it became necessary to look into the reforms to the Public Services as far as human resource management was concerned. The following sections lay down the state of affairs in this area and propose an analysis of the pertinence and efficacy of such reforms from an accountability perspective.

This exploratory study is a response to the increasing public demand globally for more transparency and accountability in public sector operations. We use available data from publications and government reports to study the history, achievements and challenges of human resource management in the public sector of Mauritius.

Globalization, or "the increasing and intensified flows between countries of goods, services, capital, ideas, information and people, which produce national cross-border integration of a number of economic, social and cultural activities," is the greatest driver of change today. It demands complex decision-making processes to take place at sub-national, national and trans-national levels, leading to a multi-layered system of governance. Governance, or "the exercise of economic, political and administrative authority to manage a country's affairs at all levels," in this context needs to adapt to these new realities. "Increasingly, the State is called upon to act as a linking pin of processes of planning, consultations, negotiation and decision-making, involving diverse players, State and non-State, at different levels of governance.” In this sense, a review of the state of a responsible and responsive HR function is being demand-driven from policy-makers and business investors alike. Granted, Mauritius has succeeded in positioning itself to face these new challenges and opportunities of the investment frenzy in the Sub-Saharan African region are fighting-fit to benefit from its advantages as a 'Gateway to Africa." Still, a modern and efficient public sector is critical to meet the new imperatives of this new economic order, and one key component of this formula is the performance and accountability of public institutions, so as to attract business and investment, but also to promote Public-Private collaborations, involve civil society, and to improve the quality of human resources. But is public-sector HR delivering on its assumed role? How accountable is the function to the country? The payoffs from HRM accountability measures are well articulated by Jack Phillips [3] in his book, and he justifies an accountability perspective by stating its benefits, as follows:

- It will serve to identify HRM's contribution to organizational effectiveness.

- It will determine whether HRM is accomplishing its objectives.

- It will help to identify the strengths and weaknesses of HRM processes.

- It is a means to calculate the return on investment in an HRM program.

- It will determine if an HRM program or policy justifies investment of resources.

- It will establish a database that can assist management in making decisions about HRM.

\section{Specific Context of Mauritius-The "Tiger" of the Indian Ocean}

Mauritius is an island in the Indian Ocean, East of Madagascar, colonized by the French, then the British, from whom it gained its independence in 1968. Often referred to as the most cosmopolitan island under the sun, Mauritius comprises a non-indigenous population of peoples descending from Indian, Chinese, European and African origin. Economically, Mauritius is an upper-middle income economy with a GDP per capita of over USD 8000, and one of the most resilient throughout Sub-Saharan Africa, and ranks an honorable $19^{\text {th }}$ (out of 185 ) for 'ease of doing business' [4]. It has, since its independence, pursued a liberal and open economic policy focusing on growth and employment while maintaining an elaborate social welfare system, which has led to a resilient economy with high growth and a diversified economic structure [5].

A brief history will lay the backdrop that can explain this enviable position: during the late 1980s and at the start of 1990s, the island's economy had significantly reduced its dependence on agriculture and its base became more diversified. Thus, the diversification strategy in the 1990s focused on consolidating and modernizing traditional economic sectors (agriculture and tourism) while creating new areas of growth which would allow the 
economy to embark on higher levels of development. The services sector, more particularly financial services, had been earmarked as the area for further economic development. By early 2013, the major pillars of the Mauritian economy were manufacturing, real estate, finance, trade and communications, ICT, and a few emerging sectors like the Sea Food Hub, the latter now absorbed into the much larger vision of the country as being not an island, but an "Ocean State" in an exclusive economic zone of about 2.4 million square kilometres. The island of Mauritius itself covers just $2000 \mathrm{~km}^{2}$. Between 1980 and 2010, Human Development Indicator (HDI) for Mauritius rose by 1.0 percent annually from 0.525 to 0.701 , which gives the country a rank of 72 out of 169 countries with comparable data. Mauritius is above the regional average, the HDI of Sub-Saharan Africa region increasing from 0.293 in 1980 to 0.389 in 2010 [4]. The Civil Service, which was developed around 1900 after the British took over a French system of administration, is still characterized by a complex network of rules and regulations, high formality, a multiplicity of grades, and a long chain of command. Post independence, the ministerial system supplanted the colonial structure, with attempts in the 70's and 80's to convert the Public Service into an instrument of development policy. In effect, it was in the face of the acute economic problems faced by the country in the early 1980's that part of the blame was attributed to the inefficiency of the Public Service. An articulated 'political will' found its reflection in the 1998 edition of the Report of the Pay Research Bureau (PRB), wherein Government expressed its commitment to reform the public sector with a view to improving service delivery and strengthening the process of public policy and decision making in that sector [6]. Successive reports have all but repeated the exact recommendations since.

The UN, in its Country Program Document for Mauritius (2009-2011) acknowledged political and economic stability and progress at all levels, and led to a qualitative leap in strategic thinking [7]. As from 2005, the vision of the government was to "transform Mauritius into an intelligent nation" by developing a "culture of achievement and excellence" and promoting "an efficient and effective education and training system that is inclusive and integrated, comprehensive and holistic” [8]. Government was committed to a 10-year reform program and followed the Program Based-Budgeting (PBB) to ensure good governance, transparency and accountability. In fact the PRB Report 2013 emphasized that the salient features of Civil Service Reforms include the "endowment of Public Service Human Resource Management reforms as a critical component of the agenda on reforms in order to achieve greater efficiency" [9]. However, whilst Government has been taking laudable initiatives to make the Public Service's recruitment and selection policies more transparent, yet these are still perceived to lack real commitment and are mostly paid lip service to. The institutional arrangements to promote integrity, transparency and accountability remained weak. As such, the society at large is at risk to favoritism and nonexistent or weak organizational ethics that easily penetrate and corrupt decisions and practices.

\section{Public Sector HRM-A Conceptual Framework}

Human Resource Management is a distinctive approach to employment management which seeks to achieve competitive advantage through strategic deployment of highly committed and highly capable workforce using an integrated array of cultural, structural and personal techniques. According to Schuler [10], strategic HRM includes “..... all those activities affecting the behavior of individuals in their efforts to formulate and implement the strategic needs of the business resulting from the organization's strategy”. According to Guest [11], if a set of HRM practices are applied consistently, and strategically, then a set of favorable outcomes will occur in terms of behavior outcomes, performance outcomes and financial outcomes. For this to happen, the HRM strategy should be should be part of the organization's strategy, and be based on focus, differentiation and cost at the same time.

HRM accountability is a continuous cycle, or system. A systemic approach enables a department or organization to identify, collect, and use the information or data on which accountability is ultimately based. HRM accountability starts with identifying the organization's strategic goals. Following that, the organization's HR goals in support of the strategic goals are defined. Then, performance measures are developed and a baseline established to permit assessment of whether the goals are being met. For example, the National Academy of Public Administration (NAPA) identified in its report, Measuring Results: Successful Human Resources Management, four major aspects of HR that should be measured: costs, customer satisfaction, workforce capacity, and process effectiveness [12]. Thus, establishing goals and measures in these four areas will help an organization identify the contribution of HRM to mission accomplishment.

A Human Resources Management Accountability System is based on the following simple premise: HRM 
does not exist as an end in itself but for the purpose of supporting organizational mission accomplishment. The head of a Ministry is thus not a free agent when it comes to managing people, in the sense that HR systems and processes cannot take on a life of their own independent of broad organizational goals. They must instead be judged by how well they, and the functional experts who administer them, support those who work each day to carry out a Ministry’s programs. This is not a new premise. "Let managers manage,” as the saying goes, and let that include managing people. Yet, the people-management structures, such as centralization of policy within the Civil Service Ministry, centralization of recruitment, and centralization of pay determination for the whole service can represent a real challenge when it comes to changing from administrative 'Personnel Management' to strategic HRM. The primary concern under Personnel Management was traditionally for compliance with procedure and legislation, and not how well the HR system supported mission accomplishment. A new Accountability model, however, would not abandon compliance concern but rather represent a major shift in balance toward outcomes and results. The new, though still evolving, HRM model places the direct responsibility for human resources management on those whose immediate task is mission accomplishment-line managers. These managers, supported by the specialist HR staff, must be given authority to manage human resources and then be held accountable for the results or outcomes of their decisions. This only makes good management sense. Those with authority and responsibility for accomplishing a Ministry's mission should also have authority and responsibility over HRM.

As we can see, HRM is an essential element of management and strategy, and there is an important place for specific HRM goals in any process or strategy aiming at transparency, efficiency, results-orientedness, and accountability. HRM accountability should be seen as a continuous cycle, or system. A systemic approach enables identification, collection, and use of the information or data on which accountability is ultimately based. It overcomes the common problem of fragmented and disjointed efforts that don't add up to the sum of their parts.

The need for HRM accountability is inherent in the delegations that Department Heads would receive from the Head of the Civil Service to hire staff, compensate them, and to use this resource in accomplishing the mission of the Public Service. Such delegated authorities are critical and potent, requiring judicious and informed use. They also must be tied to Ministerial mission-related goals. Ministries that establish goals for using their human resources management authority should be driven by the pursuit of excellence in human resources programs and systems. These goals will have their greatest impact when they are clearly connected to society's values as well as to sound management practice.

\section{Performance Management and HR Accountability in the Mauritius Public Service}

Dave Ulrich states in his article, A New Mandate for Human Resources, "the competitive forces that managers face today and will continue to confront in the future demand organizational excellence [13]. The efforts to achieve such excellence--through a focus on learning, quality, teamwork, and reengineering--are driven by the way organizations get things done and how they treat their people. Those are fundamental HR issues.” As a result, the focus is no longer on serving the individual employee and paperwork processing, but on the effective use of human resources-people-in achieving the organization's strategic objectives.

Currently, defined policy for the strategic management of human resources in the public sector is demonstrated through a commitment to the Performance Management System, supported by an agenda for training and development of staff, and an expected spillover effect from the Program Based Budgeting system. McCourt \& Ramgutty-Wong noted that severe limits to strategic HRM were present in the Civil Service of Mauritius [14]. Successive Governments have attempted some change in the work culture of the Civil Service, through various Steering and reform programs mentioned earlier in this paper. Current ills, apart from the image of inefficiency and complacency, include the inability of management to bring about visible change, the shortage of qualified personnel in key areas, the appointment of foreigners in strategic positions, the absence of career development prospects, poor working conditions, and unattractive remuneration packages [15]. Although there have been several initiatives for reforms, yet these have been slow in implementation and been met with resistance, notably by unions, largely due to the strong perception of lack of transparency and political interference in operational matters and the absence of coordination between different public bodies/institutions.

In 1994, the Ministry for Civil Service Affairs and Administrative Reforms introduced PMS on a pilot basis in four Ministries. However, in 1998 it became clear that the good intentions had not been met with proportionate trust and conviction. The 2003 and 2008 PRB Reports continued to stress on the need for a proper and 
complete implementation of the PMS, and in 1998, the Bureau highlighted in its Report that the two "landmark" programs, the PMS and the Program Based Budgeting (PBB) were complementary and essential parts of the vision of improving efficiency and accountability in the public sector, as resources would focus on results rather than inputs [6]. The Bureau states its conviction that PMS is central within an HRM system and that there is no question of delaying the full implementation (due to start in January 2013), all the while acknowledging that implementation of PMS was universally known to be a great challenge. Accordingly, a survey was conducted by the Bureau to take stock of implementation accomplishments and blockages alike [9]. Many positive results were noted amongst those Ministries (37\%) that had fully implemented the PMS, but many findings were points of concern, namely:

- For many, it was not clear how PLM was promoting organizational goals

- Many were not convinced about how PMS would help in their career or promotion;

- Less than a quarter of all organizations reported having been able to use the PMS as a basis for staff training plans or for promotion decisions;

- The appraisal forms were cumbersome and unrealistic

- PMS seemed to be missing the point of addressing real management challenges

- The critical ingredient of senior management "focus" and commitment to PMS in order to make it work was simply not present

These findings do echo what already exists in many case study reports and literature reviews, wherein we find that performance management systems seem to fall foul of their lofty ideals ([16]-[20]) In early 2013, a survey of 1000 companies worldwide shed light on performance management practices showed that, while performance management continue to be of "critical interest worldwide", very few companies (3\%) reported that their PMS delivers exceptional value [21]

A PBB system, for its part, is a driving force behind the emphasis on identifying goals and measures. Application of PBB is pushing public sector departments and ministries in the direction of aligning all their activities, including HRM, toward achieving strategic goals and measuring progress toward those goals, in an effort to improve the confidence of the public in the Government. This process has many benefits. It can help an organization clarify future direction, establish priorities, initiate program performance improvement, increase effectiveness and accountability, help managers improve service delivery, and improve decision-making and internal management. But from good intentions to real implementation, the gap is yet to be addressed.

\section{A Discussion of Constraints and Realities}

The basic premise that Human resources management exists to support "organizational mission accomplishment" is here under question. We have seen that HRM accountability is about the responsibility shared by top management, line managers, and the HR staff for ensuring that people are used effectively, and in accordance with legal requirements. We will now consider the potential for HR Accountability in the Public Service of Mauritius, against the backdrop of the accomplishments and failures of the PMS.

Most organizations, in the first place, acknowledge the need for accountability-based HRM, but are confused about how and where to start. The basic challenge in the case of the Mauritian Public Sector is how to instill ownership for HR decisions that are supposed to be made in support of mission accomplishment. The following constraints may be identified in the analysis:

- Performance objectives are not derived from the mission and roles of individual ministries or departments;

- Specific work practices and conduct are not properly and accurately measured and the determination of behavioral criteria are left to the subjective discretion of managers, allowing error, subjectivity, bias and favoritism to influence the performance rating;

- Feedback is not provided accurately and immediately (a lack of feedback and transparency in assessment create an impression of arbitrariness, besides retarding the learning of desired practices and the avoidance of undesired ones);

- Rewards and sanctions are not currently tied to the performance evaluated;

- The HR staff must first be strategic partners with the senior management of the organisation and be more results-oriented and use tools to link goals to performance that can be measured and linked to rewards. HR staff should therefore be continuously trained and developed to be able to cater for this. HR should have a clear understanding of how HRM decisions affect the organization's mission accomplishment and how corporate-level decisions have an impact upon people. Yet, we do not have evidence of this. 
- Senior management should recognize and continuously communicate that people are valuable. They should also demonstrate strong commitment to HRM accountability. In Mauritius, a predominantly Capitalistic society where management's attention is focused on their interest and on cutting costs, many State and parastatal organizations also adopt the 'hard HRM' approach which emphasizes the 'resource' side of human resources rather than the 'human' aspects of HRM [22] 'Soft HRM' entails treating employees as valued assets, a source of competitive advantage through employees' commitment, adaptability and high quality, but this is simply not the current culture. An HRM Accountability system can only work in a culture where people are valued and depended on to get the expected outcomes towards organizational objectives;

- HRM education and training should be one of the top items on the management agenda. Training, though very present, is done mostly on seniority basis. The involvement of line managers is very important but minimized in practice;

- Poor selection decisions create frustration among employees, and people end up alienated from organizational vision, mission and goals;

- Another issue is heavy-handed political intervention within the public sector. The generalized perception is that many recruitments are done on the basis of political patronage without any care for strategic imperatives or impact;

- Line managers heavily resist change and the predominant culture is difficult to change without prior top management's involvement and blessing;

- The mission and vision of the various Ministries are either unknown to the people or the latter have not ever participated in the formulation of the vision, mission, and goals;

- The public service needs to seek and obtain feedback from its stakeholders and integrate this into the different HR policies in such a way as to work towards working coherently across different departments and Ministries on a commonly-held vision;

- It can often be seen that HR decisions are taken within the central ministry without consultation with line ministries, and we observe that line managers are loathe assuming accountability of the performance of their staff when they (the managers) have so little control over selection, promotion and even training decisions. In other words, they must make do with people who others have selected, and often such decisions are tainted with interference. How then can HR be accountable for staff, for ensuring the latter follow its vision and culture when is not accountable for the very beginning of the HR process? The concept of "shared accountability" calls on managers and HR staff to work as partners in driving forward HRM performance.

- The highly politicized societal environment might be a deterrent to developing a service according to an HR accountability system, as the latter might hit against some or other pressure group's lobby and the latter's influence on politicians.

- HR Accountability system can only work if there is proper performance management. Performance measures reflect the effectiveness of human resources management and promote accountability for HRM decisions.

- Again, in the case of para-statal bodies, which operate under a given Ministry, not much can be done without the approval of the Ministry. In fact, despite the existence of Board of Directors, if the Ministry does not approve of their decisions, then nothing can be done. This begs the question as to how will a participatory approach to setting goals ever be possible.

- The public sector is accountable to the government of the day, and has to answer the Public Accounts Committee, and Parliamentary Questions (PQs) at the National Assembly. The public sector, unlike the private sector, does not have a profit focus. However, political interference, budgetary constraints, top-down management approach, one way communication, and centralized recruitment and selection mechanisms are definite barriers to the HRM Accountability System.

- The Financial impact of introducing an HRM accountability system may cause great constraint in its maintenance.

These deficiencies and the associated risk of malpractices largely explain the stagnation in the performance often found in public sector organizations. A weak state of integrity and accountability are natural consequences of the absence of a rigorous and professionally-designed performance management and accountability system.

\section{Conclusions}

Transforming the Public Service into an instrument capable of fulfilling its role in bringing about Africa's “First 
Tiger Economy" [23] depends on many factors, but above all, it depends on effectiveness of its workforce, which in turn depends on the way in which those employees are managed. Human resource management is therefore, rightly regarded as one of the strategic instruments within the transformation agenda for the Public Service.

Integrity, transparency, and accountability in HRM do not function or exist in a vacuum. Their strength is derived, to a great extent, from other core dimensions; competence or merit, ethics and professionalism. When public sector organizations focus primarily on outputs and outcomes without incorporating ethics and behavioral requirements into the accountability framework, they may be at risk. This phenomenon penetrates all levels of the administrative hierarchy. The incentive structure applied in the government, (being tied to adherence to formal rules, regulations and procedures), further reinforces formal and bureaucratically-driven accountability. The lack of control over HR utilization and impact assessment of HRM decisions widens the opportunity for malpractices and corruption, not to mention under-performance.

A competence-driven reform HRM provides the infrastructure and foundation for integrity, transparency and accountability and an associated ethics regime. Therefore, comprehensive reforms are needed in the various domains of HRM (e.g. HR planning, recruitment, selection, employment, compensation, career planning, and so on). There must be an improvement in the validity of various assessment procedures and criteria used in recruitment and selection, performance appraisal, training, promotion, interviews, and rewards. Basing these assessment procedures on clearly defined and measurable criteria channels accountability towards rational ends and reduces opportunities to misuse of power and influence. Therefore, a greater focus should be given to reforming HRM in government and should be formulated within an overall strategy. Such reforms are prerequisites to combating corruption and strengthening integrity and accountability in government thereby ensuring effective service to the citizens of Mauritius.

The close review of HR policies and practices in the public sector of Mauritius has served as basis for drawing these conclusions. As the term HRM is defined as a distinctive approach to employment management which seeks to achieve competitive advantage through strategic deployment of highly committed and capable workforce, using an integrated array of cultural, structural and personal techniques [24], a diagnosis of good practices and gaps in policies and programs is a pre-requisite to improve transparency and accountability in the public sector. It will also assist governments, regional organizations, donors and the wider public in making public policy choices and prioritizing resource allocation. As we have seen, HRM is an essential element of management, and we believe strongly that there is an important place for specific HRM goals in the overall vision of a more performing and efficient Public Service.

Serving these ends requires competent, professional and ethically strong public servants. We have seen that numerous constraints exist that can hinder the achievement of this mission.

Finally, we try to remind ourselves that, while extremely important, an accountability system within a "hard" HRM culture will bring less than meaningful results. Measures in themselves are not everything. Measures should be derived from agreed-upon goals, and when selected they must be communicated, data collected and interpreted, and actions taken as a result. Otherwise, measurement becomes an empty exercise. All measures must fit into the broader accountability system, itself emanating from a clear understanding of, and commitment to, the strategic goals.

\section{Acknowledgements}

Thanks to students of 2011 MSc Human Resource Studies of the University of Mauritius, for their valuable inputs to this study.

\section{References}

[1] (2013) World Bank Doing Business Report, 2013

[2] Fiscal Year 2014 Budget of the Government of Mauritius: Building a better Mauritius. MOFED, Government of Mauritius.

[3] Phillips, J. (1996) Accountability in Human Resource Management, Gulf Publishing.

[4] World Bank Doing Business Report 2013.

[5] Country Programme Document (Mauritius), United Nations Development Programme, 2013-2016. 
[6] (1988) Report of the Pay Research Bureau. Mauritius.

[7] Country Programme Document (Mauritius), United Nations Development Programme, 2009-2011.

[8] Strategic Plan 2008-2020_EHRSP (MOECHR, 2009: 1), Government of Mauritius.

[9] (2013)Report of the Pay Research Bureau. Mauritius.

[10] Schuler, R.S. (1993, 2006) Strategic Human Resources Management: Linking the People with the Strategic Needs of the Business. John Wiley.

[11] Guest, D. (1987) Human Resource Management and Industrial Relations. Journal of Management Studies, 24, 503521. http://dx.doi.org/10.1111/j.1467-6486.1987.tb00460.x

[12] National Academy of Public Administration (NAPA) (1997) Measuring Results: Successful Human Resources Management.

[13] Ulrich, D. (1998) A New Mandate for Human Resources. Harvard Business Review.

[14] McCourt, W. and Ramgutty-Wong, A. (2003) Limits to Strategic HRM: The Case of the Mauritian Civil Service. The International Journal of Human Resource Management, 14. http://dx.doi.org/10.1080/0958519032000057790

[15] Baguant, P. and Ramgutty-Wong, A. (2006) The Transition from Industrial Relations to Employee Relations: A Myth or a Reality? The 14th International Employment Relations Association Conference, an East-West Perspective on Work-Life Balance, Hong Kong, 19-23 June 2006.

[16] Lange, T. (2013) Evidence-Based HRM: A Scholarship Perspective with a Difference. Evidence-Based HRM: A Global Forum for Empirical Scholarship, 1, 4-15.

[17] de Waal, A. and Harold Counet, H. (2009) Lessons Learned from Performance Management Systems Implementations. International Journal of Productivity and Performance Management, 58, 367-390. http://dx.doi.org/10.1108/17410400910951026

[18] Holloway, K. (2009) Performance Management from Multiple Perspectives: Taking Stock. International Journal of Productivity and Performance Management, 58, 391-399. http://dx.doi.org/10.1108/17410400910951035

[19] Bourne, M., Pavlov, A., Franco-Santos, M., Lucianetti, L. and Mura, M. (2013) Generating Organisational Performance: The Contributing Effects of Performance Measurement and Human Resource Management Practices. International Journal of Operations and Production Management, 33, 1599-1622. http://dx.doi.org/10.1108/IJOPM-07-2010-0200

[20] Battisti, G. and Iona, A. (2009) The UK productivity Gap in the Service Sector: Do Management Practices Matter? International Journal of Productivity and Performance Management, 58, 727-747.

[21] Global Performance Management Survey Report (Sept 2013) Mercer.

[22] Storey, J. (1992) Development in the Management of Human Resources. Blackwell, Oxford.

[23] Grant Thornton, Mauritius

[24] Storey, J. (1995) Human Resource Management: A Critical Text. Routledge, London. 